\title{
A Review of the Monograph by D.L. Motov and M.M. Godneva Fluoric, Sulfatic, and Fluorosulfatic Compounds of Group IV Elements: Forming and Properties
}

DOI: $10.1134 / \mathrm{S} 1063774510030272$

The monograph deals with the formation and principal characteristics of fluorides, sulfates and fluorosulfates of the group IV elements. Presenting the results of numerous experimental studies of the authors published and translated in English earlier it also provides analysis of the currently available literature.

The 21 physical-chemical systems and 8 sections examined by the authors are described from the viewpoint of formation of their compounds in aqueous media, with demarcating the formation regions, determining the chemical composition and key characteristics such as refractometric, roentgenometric, IR-spectroscopic, thermal, including the data on heat treatment.

Systematic studying the systems has resulted in discovery of more than a hundred of new compounds and determining their structural parameters and types of chemical bonds which, when compared with known data, has allowed to identify a new class of compounds - fluorosulfatemetallates.

By comparing the systematized compounds, represented by 37 series and 9 groups and including 400 items, there has been predicted the possibility of the formation of about 30 new compounds of titanium, zirconium and hafnium with various outersphere cations.

Apart from its chemical content, the book may serve as an atlas of infrared absorption spectra, derivatograms, roentgenometric, refractometric and crystallographic data on the compounds discussed.

The monograph be of interest for researchers involved in studies of transition elements chemistry, in running the manufacturing processes concerned with fluorine chemistry as well as for college professors and students of relevant specialities.

N.N. Grishin, Dr. Sci. (Chemistry) 